\title{
Effectiveness of Educational Intervention on Knowledge Regarding Child Abuse among School Students in a Sub-Metropolitan City
}

\author{
Reena Ishwar ${ }^{*}$, Dilip Kumar Ishwar ${ }^{2}$, Punita Yadav ${ }^{3}$
}

${ }^{1}$ Bagmati Welfare Society Nepal, Sarlahi, Nepal, 2 Urban Health Promotion Center, Janakpurdham, Nepal

${ }^{3}$ Department of Nursing, Krishna Medical and Technical Research Centre, Janakpurdham, Nepal

\author{
ARTICLE INFO \\ Article history: \\ Received: 17 March 2021 \\ Revised: 27 April 2021 \\ Accepted: 11 June 2021 \\ *Correspondence: \\ Reena Ishwar \\ Bagmati Welfare Society \\ Nepal, Sarlahi, Nepal \\ E-mail: \\ ishwarreena321@gmail.com \\ Citation: \\ Ishwar R, Ishwar DK, Yadav \\ P. Effectiveness of \\ Educational Intervention on \\ Knowledge Regarding Child \\ Abuse among School \\ Students in a Sub- \\ Metropolitan City. MedS. J. \\ Med. Sci. 2021;1(1):59-66
}

\begin{abstract}
ABSTARCT
INTRODUCTION: Child abuse or maltreatment constitutes all forms of physical and/or emotional ill-treatment resulting in actual or potential harm to the child's health, survival, development. The objective was focused to measure the effectiveness of educational intervention on knowledge regarding child abuse among school students at Janakpurdham, submetropolitan city. MATERIALS AND METHODS: This study was conducted in Janaki higher secondary english school, at Janakpurdham, Dhanusha. One group pre-test and post-test design was used. A self- administered structured questionnaire was developed to assess the knowledge regarding child abuse among participants. Differential and inferential statistics were used to analyse data by SPSS package. RESULTS: Out of total 44 participants, 12 (27.3\%) participants had poor level of knowledge in pre-test whereas none had poor knowledge in post-test. $25(56.8 \%)$ participants had average level of knowledge in pre-test but only $15(34.1 \%)$ had average level in post- test. 7 (15.9\%) participants had good level of knowledge in pre-test, however 29 (65.9\%) had good level of knowledge in post-test. The scores of pre-test 18.80 (3.87) and post-test 24.23 (2.78) were found to be statistically significant. There was no any association between level of knowledge in pre-test and post-test with their selected socio-demographic variables except sex, education status of mother and occupation of father in post-test. CONCLUSIONS: Majority of participants had average level of knowledge in pre-test that was increased to good knowledge in post-test. The scores of pre-test and post-test were found to be statistically significant which determined the effectiveness of educational intervention programme.
\end{abstract}

Keywords: Child abuse, educational intervention, knowledge.

\section{INTRODUCTION}

Child abuse or maltreatment constitutes all forms of physical and/or emotional ill-treatment, sexual abuse, neglect or negligent treatment or commercial or other exploitation, resulting in actual or potential harm to the child's health, survival, development or dignity in the context of a relationship of responsibility, trust or power [1]. Child maltreatment, physical, sexual and emotional abuse as well as neglect including child labor, is a widespread phenomenon in many societies in which $25 \%$ of all adults have experienced some form of physical abuse and $20 \%$ of women have experienced sexual abuse. Worldwide $22.6 \%$ people are physically abused children, $36.3 \%$ experience emotional abuse and
$16.3 \%$ face physical neglect [2]. According to Millennium Development Goal (MDGs), goal 3 "promote gender equality and empower women" emphasized Nepal has made good progress between 1990 and 2015 in achieving gender parity for access to primary, secondary and tertiary education [3]. However, there is scanty information available on child abuse in province 2 of Nepal. No concrete data is accessible in Janakpurdham till now. Therefore, the objective of this study was focused to measure the effectiveness of educational intervention programme on knowledge regarding child abuse among school students at Janakpurdham, Submetropolitan city. 


\section{MATERIALS AND METHODS}

Study design and setting

A pre-experimental, one group pre-test and posttest research was designed. Study sample were selected based on non-probability, purposive sampling technique at Janaki Higher Secondary Boarding School, Janakpurdham, sub-metropolitan city. A total of 44 students were present at the time of data collection. As child abuse is increasing in Janakpur day-by-day resulting into physical, emotional and sexual neglect among adolescents. No research has been conducted in Janakpurdham in institutional area for child abuse.

\section{Sample size and sampling}

Students willing to participate and aged between 13-16 years who were available at the time of data collection were included in this study. Students who were sick, absent and not interested were excluded from this study.

\section{Data collection}

A self- administered structured questionnaire was developed to assess knowledge regarding child abuse among students. All the selected respondents were kept in a class and were explained about the objectives and informed

\section{RESULTS}

\section{Socio-demographic characteristics}

Table 1 shows socio-demographic characteristics of participants. Out of total 44 participants, one participant was of age 13 years, 8 (18.2\%) participants were of age 14 years, 27 (61.4\%) participants were of age 15 years and 8(18.2\%) participants were of age 16 years. Similarly, minimum annual income of participants family was NRs. 20,000/-, maximum annual income of participants family was NRs. 9,60,000/- and the annual mean income of the participants family was NRs. 2,63,886/-.

Responses for the questions regarding knowledge on child abuse are presented in Table 2.

Table 3 shows that, out of total 44 participants in pre-test, 12 (27.3\%) have poor level of knowledge, verbal consent was obtained before data collection. For pre-test, self-administered questionnaire was given to each student. Filled up questionnaire was collected and educational intervention on child abuse was given after pre-test on the same day. Post-test was done on the following day.

Scoring System: Correct response was scored as '1' and incorrect response as ' 0 '. The level of knowledge was categorized on the basis of following: Good knowledge: 75\% score; Average knowledge: 50-75\% score; Poor knowledge: $\leq 50 \%$ score [24]. Work approval letter was taken from Krishna Medical and Technical Research Center, Janakpurdham (Ref-08/075/076). Additionally, work permission letter for data collection was also obtained from Janaki Higher Secondary Boarding School, Janakpurdham-2 (Ref-24/075/076).

\section{Statistical considerations}

The filled questionnaire was rechecked, organized, coded and entered in EpiData v3.1 and exported to SPSS 16.0 version for the analysis. Descriptive statistics and inferential statistics were used to analyze the data.

$25(56.8 \%)$ have average level of knowledge and 7 $(15.9 \%)$ have good level of knowledge in pre-test. Out of total 44 participants in post-test, 15 (34.1\%) have average level of knowledge and 29 (65.9\%) have good level of knowledge in post-test.

Table 4 shows that there was no any association between the level of knowledge in pre-test and post-test with their selected socio-demographic variables except sex, education status of mother and occupation of father in post-test.

Table 5 shows that there is a significant difference in the pre-test and post-test score. This suggests that educational intervention was effective to bring changes in the level of participants knowledge. 


\begin{tabular}{|c|c|c|c|c|c|}
\hline Variables & $n$ & $\%$ & Variables & $n$ & $\%$ \\
\hline Age & & & Father's education & & \\
\hline 13 & 1 & 2.3 & Illiterate & 2 & 4.5 \\
\hline 14 & 8 & 18.2 & Primary education & 8 & 18.2 \\
\hline 15 & 27 & 61.4 & Lower secondary education & 5 & 11.4 \\
\hline 16 & 8 & 18.2 & Secondary education & 13 & 29.4 \\
\hline Sex & & & Higher secondaryor above & 16 & 36.4 \\
\hline Male & 26 & 59.1 & Mother's education & & \\
\hline Female & 18 & 40.9 & Illiterate & 6 & 13.6 \\
\hline Origin of residence & & & Primary education & 14 & 31.8 \\
\hline Rural Municipality & 1 & 2.3 & Lower secondary & 11 & 25.0 \\
\hline Municipality & 3 & 6.8 & Secondary & 5 & 11.4 \\
\hline Sub-metropolitan & 40 & 90.9 & Higher secondary and above & 8 & 18.2 \\
\hline Religion & & & Father's occupation & & \\
\hline Hindu & 38 & 86.4 & Government & 5 & 11.4 \\
\hline Muslim & 6 & 13.6 & Non-government & 6 & 13.6 \\
\hline Ethnic group & & & Self-employed & 26 & 59.1 \\
\hline Disadvantaged janajatis & 1 & 2.3 & Non-paid & 6 & 13.6 \\
\hline $\begin{array}{l}\text { Disadvantaged non-dalit terai } \\
\text { caste groups }\end{array}$ & 30 & 68.2 & Retired & 1 & 2.3 \\
\hline Religious minorities & 6 & 13.6 & Mother's occupation & & \\
\hline Upper caste group & 7 & 15.9 & Government & 1 & 2.3 \\
\hline Income (in Nepali Rupees) & & & Non-government & 2 & 4.5 \\
\hline Median: & \multicolumn{2}{|c|}{ NRs. 2,63,886/- } & Self-employed & 6 & 13.6 \\
\hline $\begin{array}{l}\text { Min.: } \\
\text { Max.: }\end{array}$ & \multicolumn{2}{|c|}{$\begin{array}{l}\text { NRs. } 20,000 /- \\
\text { NRs. } 9,60,000 /-\end{array}$} & Homemaker & 35 & 79.5 \\
\hline
\end{tabular}

\begin{tabular}{|c|c|c|c|c|c|c|}
\hline \multirow{2}{*}{ S.N } & \multirow{2}{*}{ Variables } & \multirow{2}{*}{ Response } & \multicolumn{2}{|c|}{ Pre-test } & \multicolumn{2}{|c|}{ Post-test } \\
\hline & & & $\mathrm{n}$ & $\%$ & $\mathrm{n}$ & $\%$ \\
\hline 1. & Heard about child abuse & Yes & 44 & 100.0 & 44 & 100.0 \\
\hline 2. & Sources of information & & & & & \\
\hline \multirow{2}{*}{$2 \mathrm{~A}$} & \multirow{2}{*}{ Television/Radio } & Yes & 24 & 54.5 & 35 & 79.5 \\
\hline & & No & 20 & 45.5 & 9 & 20.5 \\
\hline \multirow{2}{*}{$2 \mathrm{~B}$} & \multirow{2}{*}{ Newspaper/magazines } & Yes & 23 & 52.3 & 21 & 47.7 \\
\hline & & No & 21 & 47.7 & 23 & 52.3 \\
\hline \multirow{2}{*}{$2 \mathrm{C}$} & \multirow{2}{*}{ Books } & Yes & 33 & 75.0 & 39 & 88.6 \\
\hline & & No & 11 & 25.0 & 5 & 11.4 \\
\hline \multirow{2}{*}{$2 \mathrm{D}$} & \multirow{2}{*}{ Internet } & Yes & 24 & 54.5 & 31 & 70.5 \\
\hline & & No & 20 & 45.5 & 13 & 29.5 \\
\hline \multirow{2}{*}{$2 \mathrm{E}$} & \multirow{2}{*}{ Friends/relatives } & Yes & 27 & 61.4 & 28 & 63.6 \\
\hline & & No & 17 & 38.6 & 16 & 36.4 \\
\hline \multirow{2}{*}{$2 \mathrm{~F}$} & \multirow{2}{*}{ Teachers } & Yes & 40 & 90.9 & 44 & 100.0 \\
\hline & & No & 4 & 9.1 & 0 & 0.0 \\
\hline 3. & $\begin{array}{l}\text { Child abuse is public health problem/social } \\
\text { problem }\end{array}$ & True & 44 & 100.0 & 44 & 100.0 \\
\hline \multirow{2}{*}{4.} & \multirow{2}{*}{$\begin{array}{l}\text { Child abuse is physical, psychological and } \\
\text { sexual maltreatment of children }\end{array}$} & True & 39 & 88.6 & 44 & 100.0 \\
\hline & & False & 5 & 11.4 & 0 & 0.0 \\
\hline
\end{tabular}


5. Child abuse is also known as neglect

6. Four forms of child abuse

7. Average age that child molesters first attack a child

8. Child abuse is reported in Nepal every

9

10. Single leading cause of children ages four or younger

Chances of child abuse is higher in single parent families

11. Neglect is when parents fail to meet various needs to the child.

12. Physical abuse involves striki
choking and shaking of child

Psychological abuse involves shaming or

13. ignoring, extreme punishment, withholding affection to child.

14. Sexual abuse is
involving a child.

15. Strangers pose greatest risk of sexual abuse to children

16.

Abuse greatly impacts on child's learning ability

17.

Abuse can impact a child's behaviour into adulthood

18. $90 \%$ abusers are......

19. Examples of physical abuse
True

False

Neglect,

psychological

Physical, psychological, mental,

emotional

Emotional, physical, mental,

education

Neglect, sexual, education, physical 8

In their early 20 s

Middle-aged

In their teens

10 seconds

20 minutes

Hour

second

True

False

Drowning

Motor vehicle accident

Child abuse and neglect

Choking on foods

Falls

True

False

True

False

True

False

True

False

True

False

True

False

True

False

Parents

Strangers

Someone the victim knows

Priests

Lack of food

No shelter

Bruises on legs

Fear of adults

$\begin{array}{|lll|}81.8 & 44 & 100.0 \\ 18.2 & 0 & 0.0 \\ 50.0 & 37 & 84.1 \\ & & \\ 11.4 & 4 & 9.1 \\ & & \\ 20.5 & 3 & 6.8 \\ 18.2 & 0 & 0.0 \\ 6.8 & 4 & 9.1 \\ 22.7 & 1 & 2.3 \\ 70.5 & 39 & 88.6 \\ 6.8 & 44 & 100.0 \\ 15.9 & 0 & 0.0 \\ 75.0 & 0 & 0.0 \\ 2.3 & 0 & 0.0 \\ 65.9 & 38 & 86.4 \\ 34.1 & 6 & 13.6 \\ 2.3 & 1 & 2.3 \\ 11.4 & 1 & 2.3 \\ 77.3 & 41 & 93.2 \\ 6.8 & 0 & 0.0 \\ 2.3 & 1 & 2.3 \\ 65.9 & 43 & 97.7 \\ 34.1 & 1 & 2.3 \\ 90.9 & 44 & 100.0 \\ 9.1 & 0 & 0.0 \\ 81.8 & 44 & 100.0\end{array}$

\begin{tabular}{l|lll}
8 & 18.2 & 0 & 0.0
\end{tabular}

\begin{tabular}{l|lll}
44 & 100.0 & 43 & 97.7
\end{tabular}

$\begin{array}{llll}0 & 0.0 & 1 & 2.3\end{array}$

$\begin{array}{llll}43 & 97.7 & 43 & 97.7\end{array}$

$\begin{array}{llll}1 & 2.3 & 1 & 2.3\end{array}$

$\begin{array}{llll}40 & 90.9 & 44 & 100.0\end{array}$

$\begin{array}{llll}4 & 9.1 & 0 & 0.0\end{array}$

\begin{tabular}{l|lll}
39 & 88.6 & 41 & 93.2
\end{tabular}

$\begin{array}{llll}5 & 11.4 & 3 & 6.8\end{array}$

$\begin{array}{llll}5 & 11.4 & 1 & 2.3\end{array}$

$\begin{array}{llll}25 & 56.8 & 15 & 34.1\end{array}$

$\begin{array}{llll}12 & 27.3 & 28 & 63.6\end{array}$

$\begin{array}{llll}2 & 4.5 & 0 & 0.0\end{array}$

$\begin{array}{llll}13 & 29.5 & 11 & 25.0\end{array}$

$\begin{array}{llll}2 & 4.5 & 0 & 0.0\end{array}$

\begin{tabular}{l|lll}
24 & 54.5 & 32 & 72.7
\end{tabular}

$\begin{array}{llll}5 & 11.4 & 1 & 2.3\end{array}$ 
20. Examples of emotional abuse

21. Examples of sexual abuse

22. Child abuse normally found in households with incomes of

23. Organizations work together to safeguard children

24. If you have concern about child, actions to be done:

25. Actions help to stop child abuse and neglect

Preventing child abuse is the

26. responsibility of:
Lack of confidence

Lack of social skills

Isolated from parents

All of above

Trauma

Pregnancy

The use of sexual languages

All of above

Less than $\$ 20000$

\$20000-\$35000

All of above

UNICEF and WHO

International Society for Prevention

of Child Abuse and Neglect (ISPCAN)

Both 1 and 2

Tell to someone about your concerns

Tell the child's parents

Ask the child what's going on

Ring the police immediately

Helping a stressed-out parent by baby-sitting, making a meal for their family

Learning the signs and symptoms of child abuse so you can recognize them when you see the "red flags"

Reporting known or suspected child abuse to the police or local child protective services agency

All of above

The government

Parents

\begin{tabular}{|c|c|c|c|}
\hline 7 & 15.9 & 0 & 0.0 \\
\hline 4 & 9.1 & 0 & 0.0 \\
\hline 11 & 25.0 & 16 & 36.4 \\
\hline 22 & 50.0 & 28 & 63.6 \\
\hline 0 & 0.0 & 2 & 4.5 \\
\hline 3 & 6.8 & 4 & 9.1 \\
\hline 17 & 38.6 & 20 & 45.5 \\
\hline 24 & 54.5 & 18 & 40.9 \\
\hline 28 & 63.6 & 44 & 100.0 \\
\hline 2 & 4.5 & 0 & 0.0 \\
\hline 14 & 31.8 & 0 & 0.0 \\
\hline 9 & 20.5 & 3 & 6.8 \\
\hline 9 & 20.5 & 0 & 0.0 \\
\hline 26 & 59.1 & 41 & 93.2 \\
\hline 2 & 4.5 & 0 & 0.0 \\
\hline 12 & 27.3 & 41 & 93.2 \\
\hline 2 & 4.5 & 0 & 0.0 \\
\hline 28 & 63.6 & 3 & 6.8 \\
\hline 2 & 4.5 & 0 & 0.0 \\
\hline 3 & 6.8 & 10 & 22.7 \\
\hline 9 & 20.5 & 3 & 6.8 \\
\hline 30 & 68.2 & 31 & 70.5 \\
\hline 1 & 2.3 & 0 & 0.0 \\
\hline 11 & 25.0 & 0 & 0.0 \\
\hline
\end{tabular}

Table 3 | Knowledge level in pre-test and post-test $(\mathrm{N}=44)$

\begin{tabular}{llcccc} 
& & \multicolumn{2}{c}{ Pre-test } & \multicolumn{2}{c}{ Post-test } \\
S.N & Level of knowledge & $\begin{array}{c}\text { Frequency } \\
(\mathrm{n})\end{array}$ & $\begin{array}{c}\text { Percent } \\
(\%)\end{array}$ & $\begin{array}{c}\text { Frequency } \\
(\mathrm{n})\end{array}$ & $\begin{array}{c}\text { Percent } \\
(\%)\end{array}$ \\
\cline { 2 - 6 } 1. & Poor knowledge & 12 & 27.3 & 0 & 0.0 \\
2. & Average knowledge & 25 & 56.8 & 15 & 34.1 \\
3. & Good knowledge & 7 & 15.9 & 29 & 65.9 \\
& & & & \\
& Total & 44 & 100.0 & 44 & 100.0 \\
\end{tabular}




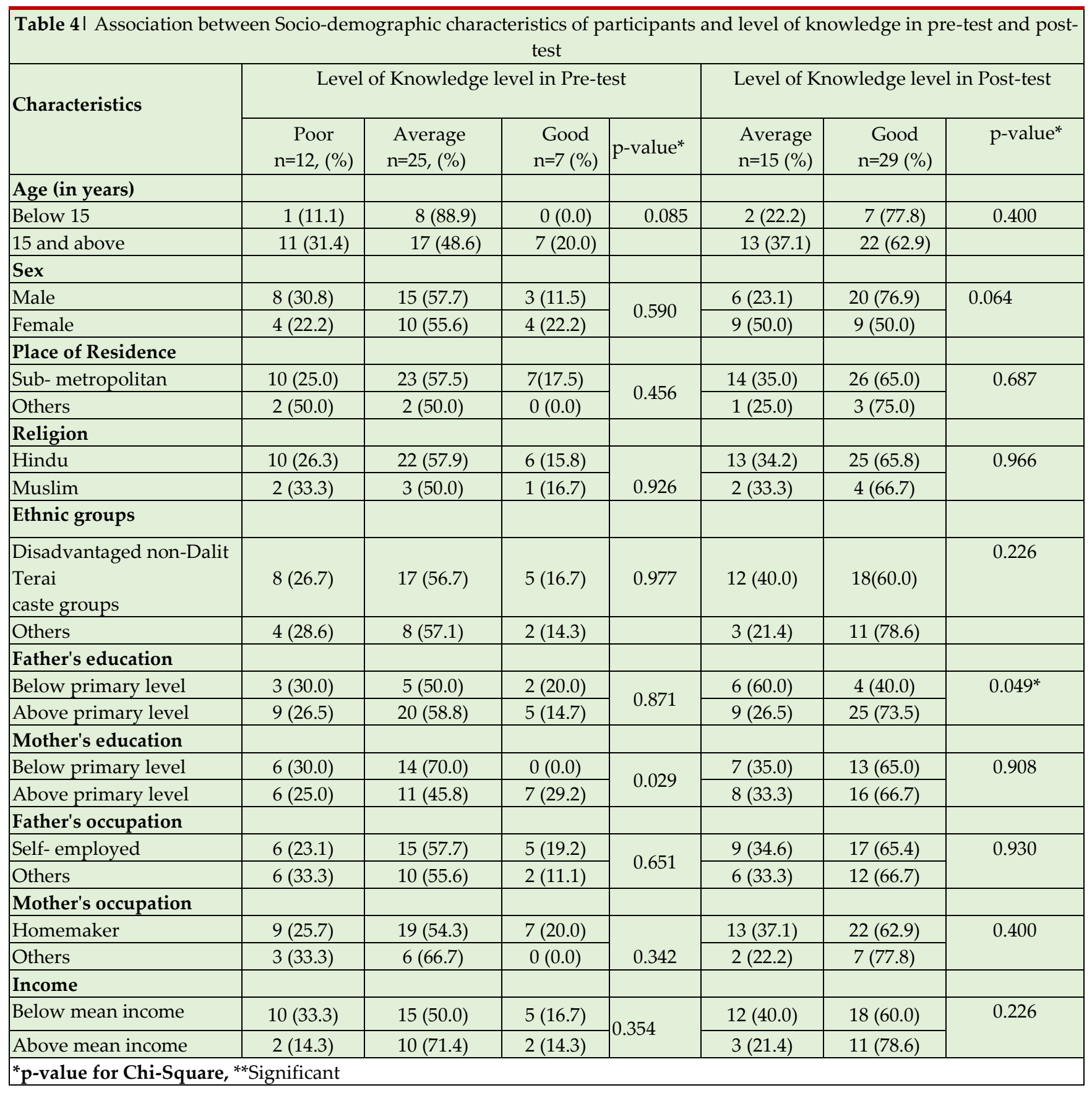

Table 5 I Effectiveness of intervention as per score in the pre-test and post-test by paired $\mathrm{t}$-test $(\mathrm{N}=44)$

$\begin{array}{crrrrr}\text { Pre-test } & \text { Post-test } & \text { T } & \text { df } & \text { p-value } & \text { Remarks } \\ \text { Mean (SD) } & \text { Mean (SD) } & & & & \end{array}$




\section{DISCUSSION}

The findings of the study showed that, $27.3 \%$ of the participants had poor level of knowledge in pretest and none of participants had poor knowledge in post-test. $56.8 \%$ of the participants had average level of knowledge in pre-test and $34.1 \%$ of the participants had average level in post-test. $15.9 \%$ of the participants had good level of knowledge in pre-test and $65.9 \%$ of the participants had good level of knowledge in post-test. However in a study carried in Vellore, India out of total 30 schoolers, experimental group nearly half of the schoolers $47 \%$ had inadequate knowledge, 30\% had moderately adequate knowledge, $23 \%$ had adequate knowledge during pre-test. In the control group $47 \%$ of the schoolers had inadequate knowledge, 33\% had moderately adequate knowledge and $20 \%$ had adequate knowledge [4].

Out of total 44 participants, the average level of knowledge among participants was 25 (56.8) in pretest which decreased to 15 (34.1) in post-test and the good level of knowledge of participants was 7 (15.9) in pre-test which increased to 29 (65.9) in post-test. None of participants had poor level of knowledge in post-test. In a similar study, out of total 44 caregivers, only one participant has poor level of awareness about child abuse. $61.4 \%$ participants had average awareness on child abuse and $36.4 \%$ participants had good awareness about child abuse. Also, out of 44 teachers, 59\% had average awareness, $41 \%$ had good awareness and none of teachers had poor awareness about child abuse [5]. Similarly, out of total 20 mothers, $15 \%$ mothers had inadequate knowledge and $85 \%$ have moderately adequate knowledge about child abuse while none of the mothers have adequate knowledge [6]. Likewise, out of total 100 mothers, $57 \%$ of the mothers had moderate knowledge and $43 \%$ of the mothers had inadequate knowledge regarding prevention and management of child abuse [7]. In this study, average level of knowledge among participants had decreased in post-test and good level of knowledge among participants had increased in post-test. Which was similar to the study conducted by Thenmozhi $\mathrm{P}$ et al. where, out of 30 school age children, $66.7 \%$ had inadequate knowledge, $33.3 \%$ had moderate knowledge and $0 \%$ had adequate knowledge in the pretest. The level of knowledge was improved after intervention and in the post-test $43.3 \%$ had moderate knowledge and $56.7 \%$ had adequate knowledge [8]. The results of Gincy, Jose, 2018 showed that, $47 \%$ had poor knowledge, $30 \%$ had average knowledge and $23 \%$ had good knowledge in pre-test. After an educational program, $40 \%$ had average knowledge and $60 \%$ had good knowledge in post-test [9].

In this study, there was no relationship between level of knowledge with their selected sociodemographic variables except sex, education status of mothers and occupation of father's occupation in post-test. In contrast to this, there was an association between awareness and education status at $5 \%$ level of significance but, all the selected demographic variables were not associated with awareness of caregivers [5]. Similarly, there was no any association between scores when compared to age, sex, occupation, religion, socio-economic status, parental status, previous source of knowledge except education status and also maximum demographic variables of parents do not affect the level of knowledge except education status [10]. In this study, the respondents belonged to $15-16$ years $(51 \%), 17-18$ years (33 \%), 13 - 14 years $(10 \%)$ and 19 years $(5 \%)$. There was no significant association found between the level of knowledge related to adolescents with their age in pre and post-test. Regarding gender of adolescents, 50\% were females and $50 \%$ were males. There was no significant association found between the level of knowledge to adolescents with their gender in pre and post-test. There is no significant association found between the level of knowledge related to adolescent with class in pre-interventional and post-interventional which is similar to the findings of study done by Kaur S. [11]. Likewise, pre-test level of knowledge regarding prevention of sexual abuse, showed that $80 \%$ of the female students had inadequate knowledge, $20 \%$ had moderately adequate and none of them had adequate knowledge. However, during the post-test $43.3 \%$ had adequate knowledge, $56.7 \%$ had moderately adequate knowledge and none of them had inadequate knowledge regarding sexual abuse. Highly significant difference was found between pre and post test scores of level of knowledge in all the areas and in the overall level of knowledge at $\mathrm{p} \leq 0.001$ level $(\mathrm{t}=15.8)$. Similar findings were also observed in study conducted by Maneesha Kaur et al. where there was no significant association 
between knowledge regarding prevention of sexual abuse among female children with their selected demographic variables at $p \leq 0.05$ level [12].

In this study, significant difference in pre-test and post-test score of knowledge on child abuse was found through paired $t$-test. Hence the educational intervention was effective. The scores in pre-test and post-test were found to be statistically significant which determined the effectiveness of educational intervention programme. In contrast to this, a study done by Deshpande A et al. found that medical and dental residents sere not sufficiently prepared to endure their roles in protection of child from being abused. A significant gap existed between recognizing signs of physical child abuse and responding effectively. Improvements in child abuse education and continuing education courses were advised to provide adequate knowledge [13].

\section{CONCLUSION}

Majority of participants have average level of knowledge in pre-test. The average knowledge of participants was decreased in post-test and good knowledge of participants was increased in post-

test. The scores in pre-test and post-test were found to be statistically significant which determined the effectiveness of educational intervention program for prevention and control of child abuse.

\section{ADDITIONAL INFORMATION AND DECLARATIONS}

Acknowledgements: Authors deep gratitude goes to the Principal of Janaki Higher Secondary Boarding School, Janakpur2, Nepal, for granting permission to carry out this study and special thanks goes to the teachers and staffs for their kind cooperation and help to carry out this research.
Funding: The authors received no funding for this work. Competing Interests: The author declare that they have no competing interests.

Data Availability: Data will be available up on request to corresponding authors after valid region.

\section{REFERENCES}

1. WHO. Child maltreatment: World Health Organization; 2016 [March 15, 2018].

2. Atteraya MS, Ebrahim NB, Gnawali S. Determinants of child 7 maltreatment in Nepal: Results from the 2014 Nepal multiple indicator cluster survey (the 2014 NMICS). Child abuse \& neglect. 2018;76:400-7.

3. Nepal Go. Nepal and the Millennium Development Goals, Final Status Report, 2000-2015. 8. Kathmandu: National Planning Commission. 2016.

4. Dhanalakshmi N, "Effectiveness of School based Educationon levels of knowledge, attitude and expressed practices regarding prevention of sexual abuse among schoolers at selected schools, Vellore", Indian Journal of Youth and Adolescent 9. Health. 2018;5(3):12-16.

5. Savitha A, Nalini M, Shetty $R$, Aruni G, Sukesh P. Awareness about Child Abuse among Care Givers and Teachers in Selected Rural Schools at Mangalore. Asian 10. Journal of Nursing Education and Research. 2016;6(4):476.

6. Thangavelu SN. Assess the level of knowledge regarding child abuse among the mothers in selected 11. Kaur S. A Pre-experimental Study areas at Latur. Journal of child and adolescent behavior. 2016;4(1):e1000271-e.

Malla, C., Rai, D., Poudel, P., \& Hodlur, S. (2018). Effectiveness of Video Assisted Teaching Programme (VATP) on Prevention and Management of Child Abuse Among Mothers of Children in Selected Rural Area, Mangalore. Med Phoenix. 3(1),66-70..

Prof. Mrs. Thenmozhi. P, Mrs. J. Uma, " A study to evaluate the Effectiveness of video assisted teaching on the knowledge regarding child abuse among school age children in selected 13 school, Coimbatore, International Journal of Scientific Research. 2019; $8(1)$.

Gincy, Jose, “Effectiveness of structured teaching programme on knowledge regarding prevention of sexual abuse among the female children in a selected school, Salem". 2018.

10. Devi AM, Yadav R. Knowledge Regarding Child Abuse among Parents. International Journal of Advances in Nursing Management. 2016;4(3):191-193. to Assess the Effectiveness of Structured Teaching Programme on Knowledge regarding Awareness about Sexual Abuse among the Adolescents studying in selected School of District Gurdaspur, Punjab. International Journal of Nursing.

12. Maneesha Kaur, Lingaraju Ar, "The Effectiveness of Structured Teaching Programme on Knowledge Regarding Child Sexual Abuse among School Age Children". International Journal ofScienceandResearch(IJSR). 2020;9(6):362 - 64 .

3. Deshpande A, Macwan C, Poonacha K, Bargale S, Dhillon S, Porwal P. Knowledge and attitude in regards to physical child abuse amongst medical and dental residents of central Gujarat: A cross-sectional survey. Journal of Indian Society of pedodontics and preventive dentistry. 2015;33(3):177. 